Rakenteiden Mekaniikka (Journal of Structural Mechanics)

Vol. 52, No 1, 2019, pp. 1-22

http://rakenteidenmekaniikka.journal.fi/index

https:/doi.org/10.23998/rm.77252

(C) 2019 The Authors

Open access under license CC BY 4.0

\title{
Structural fire analysis of simple steel structures by using LS-DYNA
}

\author{
Zhongcheng $\mathrm{Ma}^{1}$, Jarmo Havula, and Markku Heinisuo
}

Summary. Currently, structural fire design is moving from prescriptive approach to performance-based approach. One of the key essential techniques for performance-based approach is the numerical analysis technique of steel structures in fire using advanced calculation models. In this paper, the selected structural fire analysis procedure from 2D temperature analysis to structural response using LS-DYNA was studied and validated by the fire tests of a simply supported beam, a simple steel frame and a both axially and rotationally restrained steel column. 2D implicit temperature analysis is efficient in these cases and sufficient accuracy was achieved. Using explicit solver, structural response in fire can be simulated up to collapse with the considerations of the temperature-dependent material nonlinearity and possible contacts in joints. Both beam element models and shell element models were developed, and the structural responses were compared with the fire tests from literature. Results show that the developed modeling techniques using LS-DYNA explicit solver can effectively capture the key behavior of steel structures in fires. This key behavior includes deformation responses of beam and column, axial forces developed due to restraints and fire resistance time.

Keywords: structural fire analysis, 2D temperature analysis, steel structures, Hughes-Liu beam element, Belytschko-Tsay shell element, LS-DYNA explicit solver

Received 25 June 2018. Accepted 1 January 2019. Published online 11 July 2019.

\section{Introduction}

When design steel structures, structural fire safety assessment is equally important as the load-bearing design. In recent years, structural fire design is moving from current 'prescriptive' rules to performance-based method. The past fire incidents and large-scale structural fire tests such as fire event in Broadgate (1991, UK), fire tests in William Street (1992, Australia), and full-scale fire tests on a 8-storey steel-framed building in Cardington (1995, 1996, UK) [1,2, 3] revealed that the current Eurocodes, although conservative, are not addressing the true behavior of steel structures in fire since the

${ }^{1}$ Corresponding author: zhongcheng.ma@hamk.fi 
buildings are not acting as a series of individual members. It was found that the structural member in a frame had a significantly better behavior in fire than that in the standard fire resistance test. The standard fire test was very conservative by disregarding the interaction between members [4]. Therefore, performance-based method is the major trend in the structural fire safety design. The performance-based method can also significantly reduce the overall construction cost of steel structures and still produce safer design. Meanwhile, in current Eurocode 3 part 1.2, the advanced models are allowed to be used in the structural fire design of steel structures.

One of the key factors for performance-based method is the utilization of finite element analysis (FEA) techniques to simulate the structural response of building in fire [5]. This requires both the knowledge in structural fire engineering and the advance of commercial softwares (Abaqus, LS-DYNA, Ansys) in structural fire analysis. In last decades, the understanding on the structural fire behavior has increased considerably, the software functions have been developed for structural fire analysis. Increasing understanding of structural fire behavior and development in both analysis software and computer capacity enable the application of advanced calculation models in research and engineering design practice [6]. However, relevant analysis techniques need to be developed, benchmarked and validated by fire testing data. These techniques include material data and models, analysis procedures, parameter sensitivity analysis, model validations.

Recently, there is increasing interest in fire resistance simulation of steel structures using LS-DYNA [7, 8, 9]. LS-DYNA is a commercial general-purpose finite element software [19] and is one of the mostly common used explicit integration software [8]. It has been used for the aircraft impact, progressive collapse analysis of World Trade Center (WTC) by NIST [17, 18]. Rackauskaite et al [8] benchmarked four selected testing cases to study the model parameter sensitivity of structural fire analysis in case of fire using Hughes-Liu beam element by LS-DYNA explicit solver. It uses either measured or analyzed temperature histories from other literatures and software as input. Paik et al [7] conducted structural fire analysis of offshore installations in fire by shell element in the new design procedure using LS-DYNA. The structural fire analysis approach was first validated by fire test of a simply supported beam and then extend to the structural response analysis of complex frame structure. The two important parameters for fire boundary (emissivity factor and convection coefficient) were adjusted in order to fit the structural response with test. These two parameters are relatively far from the specified values from Eurocode 1 [13]. Therefore, there is also an interest to investigate the results using both fire parameters and material properties according to Eurocodes.

\section{Objectives and structural fire analysis procedure in this study}

Fire events and tests usually have long duration, lasting from a few minutes to a few hours. The analysis time using explicit solver will be extremely long if no measure is taken. In this study, three selected existing fire tests from literature were simulated using Ls Dyna. The 2D temperature analysis of the fire tests are first carried out and the results are compared with the testing measurement. Then the temperature histories and 
distribution from 2D temperature analysis are used as input for the subsequent structural response analysis. When performing 3D structural analysis, the mechanical loads are applied to the structure at first, then the heating process starts, and temperature rises inside the structure while mechanical loads are kept as constant. The mechanical loads were first applied within 200 seconds, then heating process starts and continue up to structural instability. The later process usually lasts from 900 seconds (15 minutes) to 7200 seconds (120 minutes). Due to the fact that the mechanical effect by heating process is relatively slow, there is an interest to use a consistent time scaling factor for the structural fire analysis of steel structures. A time scaling factor of 100 was used to increase the computational efficiency both for load application and heating processes in this study, the induced kinematic energy is monitored, and structural responses were compared with the tests.

In this paper, three fire tests existing in literature are modelled and the results are compared with the testing measurements. The numerical analysis techniques using Ls Dyna for structural fire analysis are explored and the selected analysis procedure is verified using both beam and shell elements. The analyses are carried out from temperature analysis to structural response in fire. The analyzed temperature distribution and history, structural deformation response and axial restraining forces are compared with testing results and previous simulation in literature using other software. It is of interest to use beam elements for larger structures in fire and shell element model can be used if local, flexural and lateral-torsional buckling failures are of interest. New fire test cases from literature are also modelled and studied in this paper.

The parameters for fire tests, such as convection coefficient and emissivity factor were taken according to Eurocode 1 [13] for all cases. Thermal and mechanical properties of steel and concrete are taken according to Eurocode $3 \& 4[14,16]$.

\section{FE modelling of simply supported beam}

\section{Description of fire test by Cong et al [15]}

The simply supported steel beam was loaded by four concentrated forces applied at locations $\mathrm{L} / 8,3 \mathrm{~L} / 8,5 \mathrm{~L} / 8$ and $7 \mathrm{~L} / 8$, where $\mathrm{L}$ is the beam span length (Fig. 1). The applied total force was $42 \mathrm{kN}$, which is equivalent to the uniformly distributed load of $10 \mathrm{kN} / \mathrm{m}$. Both supports and beam ends in $150 \mathrm{~mm}$ range were fire protected.

The simply supported beam was heated by a horizontal furnace with oil burner. The measured gas temperature is shown in Fig. 2(a). The top face of the upper flange was covered by aluminum plate and exposed to air. All other sides were directly exposed to fire. The height of the hot rolled I-section beam is $250 \mathrm{~mm}$, the flange width is $125 \mathrm{~mm}$, the flange thickness is $9 \mathrm{~mm}$ and the web thickness is $6 \mathrm{~mm}$. The span length of the beam is $4.2 \mathrm{~m}$. The measured yield strength of steel is $330 \mathrm{MPa}$ and the tensile strength is $415 \mathrm{MPa}$. 


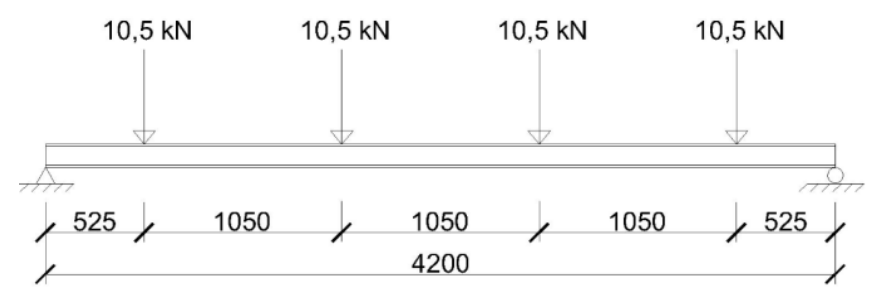

Figure 1. Simply supported beam under four-point loading.

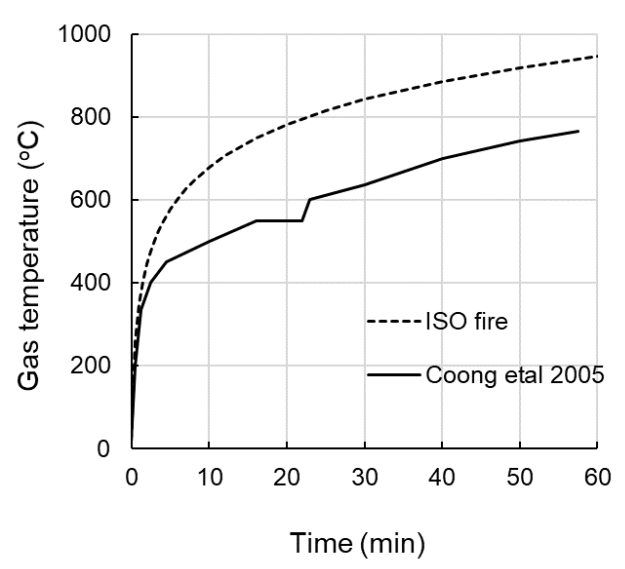

(a) gas temperature

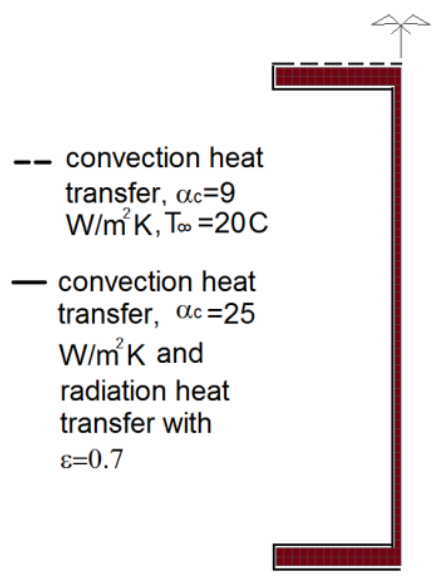

(b) $2 \mathrm{D}$ thermal model

Figure 2. Gas temperature and FE model for temperature analysis.

\section{D model for temperature analysis}

With the elevated gas temperature, the temperature of steel beam arises by radiative and convective heat transfer. The 2D FE model was created to analyze the temperature history (Fig. 2(b)). The cross-section of steel beam is heated from three sides by convection and radiation. The top side of the cross-section is directly exposed to the air of $20{ }^{\circ} \mathrm{C}$. The *Boundary_Convection_Set is defined in the 2D thermal model for convection heat transfer and *Boundary_Radiation_Set is defined for radiation heat transfer. The heat input due to convection between surfaces of steel beam and the hot gas is

$$
\dot{q}=\alpha_{c}\left(T_{s}-T_{\infty}\right)
$$

where $\alpha_{c}$ is the convection coefficient $\left(\mathrm{W} / \mathrm{m}^{2} \mathrm{~K}\right)$. According to EN 1991-1-2 [13], the convection factor of $25 \mathrm{~W} / \mathrm{m}^{2} \mathrm{~K}$ for ISO standard fire in exposed side is used in this thermal analysis, and $9 \mathrm{~W} / \mathrm{m}^{2} \mathrm{~K}$ for unexposed side. $\mathrm{T}_{\mathrm{s}}$ is the surface temperature of steel beam $\left({ }^{\circ} \mathrm{C}\right)$, and $\mathrm{T}_{\infty}$ is the gas temperature $\left({ }^{\circ} \mathrm{C}\right)$.

The heat input due to the radiation is

$$
\dot{q}=\varphi \sigma \varepsilon\left[\left(T_{s}+273\right)^{4}-\left(T_{\infty}+273\right)^{4}\right]
$$


where $\varphi$ is configuration factor, taken as 1.0 in this analysis [13]; $\sigma$ is StephanBoltzmann constant $\left(5.67 \times 10^{-8} \mathrm{~W} / \mathrm{m}^{2} \mathrm{~K}^{4}\right) ; \varepsilon$ is the resultant emissivity coefficient, taken as 0.7 in this analysis according to EN 1993-1-2 [14].

The temperature-dependent thermal conductivity and specific heat of steel material are defined according to EN 1993-1-2.

The temperature histories of the beam in the central points of lower flange, web and top flange are illustrated in Fig. 3 and compared with the test measurement from Cong et al [15]. It can be seen that the analyzed temperatures are higher than the measurement for upper flange and web and very close to the measurement for lower flange. The maximum differences are around $85{ }^{\circ} \mathrm{C}$ at 15 minutes in upper flange $(34 \%), 70{ }^{\circ} \mathrm{C}$ at 35 minutes in web $(12 \%)$, and $50{ }^{\circ} \mathrm{C}$ in lower flange at 50 minutes $(8 \%)$, respectively. In general, the agreement between analysis and measurement is good using the parameters defined according to Eurocodes for lower flange and web, relative larger difference in early phase of fire in upper flange. This is due to the heat sink effect of aluminum plate placed on top of the upper flange during the test, which is not included in the FE model.
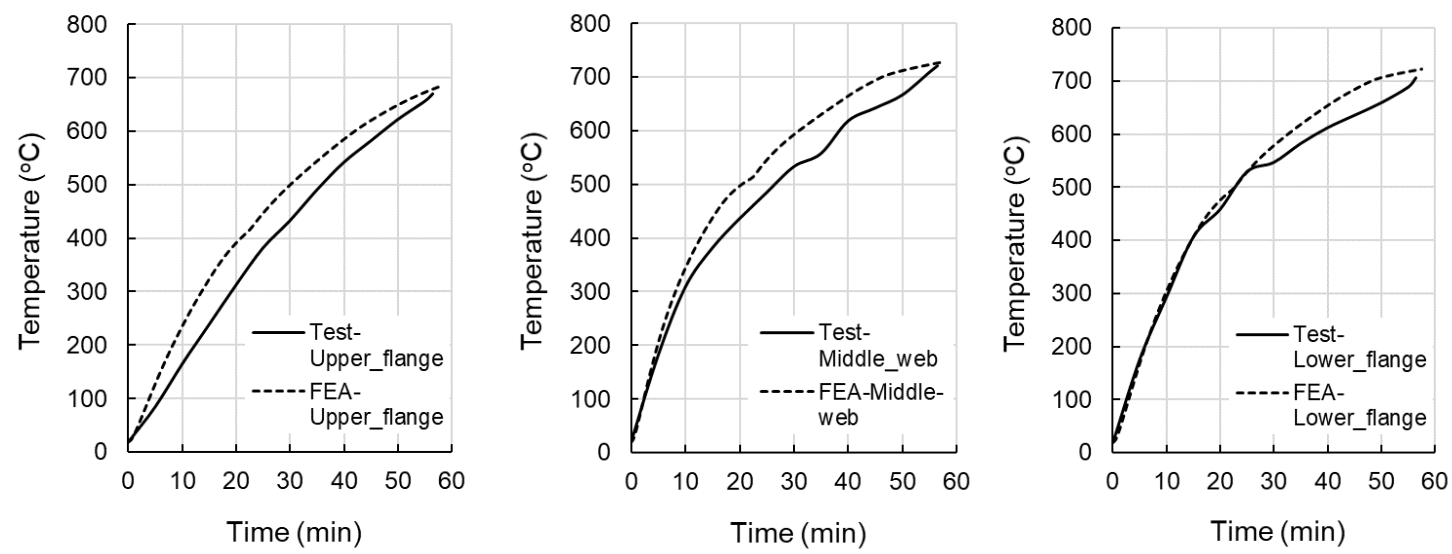

Figure 3. Temperature history of steel beam under fire.

\section{Structural analysis using beam element model}

Firstly, a FE model was created using Hughes-Liu beam elements with user-defined integration in the cross-section. A total of 39 integration points in the cross section (refinement factor $\mathrm{k}=5$ ) are defined in the model, and one integration point in the middle of the element along the length. Temperature-dependent material model MAT202 is used with updated definitions of elastic modulus, thermal expansion coefficient and plastic stress-strain curves according to EN 1993-1-2, to override the default definitions. User should be cautious with the embedded definition of MAT202 in LS-DYNA R9.01. Ununiform thermal loads were applied in LS-DYNA by *Load_Thermal_Variable_Beam_Set. The temperature distribution in the cross-section was represented by 13 points with temperature histories are defined. Five points are defined in top and bottom flanges, respectively; five points are defined along the web height. The temperature histories at these locations in the cross-section are the outputs from 2D temperature analysis. Since the temperature difference between the tips and the middle point is less than $20{ }^{\circ} \mathrm{C}$ (at 50 minutes) for both top and bottom flanges, the 
average temperature histories are used, in order to simplify the model definitions. Simply supported boundary is defined in the model. Pinned boundary condition is defined in the left end and roller boundary condition is defined in right end with free movement along the longitudinal axis. A mesh sensitivity study with the element length of $30 \mathrm{~mm}$ and $60 \mathrm{~mm}$ shows very close deformation response (maximum difference of displacement at mid-span is 1\%) (Fig. 4).

Fire analysis following real time scale is very time/resource consuming for structural analysis using explicit solver. Due to the quasi-static nature of the loading and heating processes, the actual time can be scaled to speed up the analysis. The scaling factor was studied in detail in [8]. In this case, a scale factor of 100 is used based on previous experience [20]. The static loads are applied in four loading points simultaneously and linearly increased to $10.5 \mathrm{kN}$ for each point in 2 seconds. This process corresponds to a loading duration of 3.3 minutes. Then the loading is kept constant. After that the heating process starts. The total heating time of 18 seconds is defined in the FE model which corresponds to a fire duration of 30 minutes. The further examination on the energy ratios between kinematic energy and internal energy shows that the energy ratio is $0.87 \times 10^{-4}$ for loading process and $0.11 \times 10^{-2}$ for heating process. We can conclude that the kinematic effect is insignificant, and the used scaling factor is valid.

The deformation response from FE analysis shows that the FE model is able to capture the deformational behavior of the simply supported beam using parameters and material models according to EN1993-1-2. However, according to the failure criteria defined in [12], the maximum deformation of L/20 or deformation rate of

$$
\frac{d \delta}{d t}=\frac{L^{2}}{15 h^{2}}
$$

where $\delta$ is the deformation of beam in $\mathrm{mm}, \mathrm{L}$ is the beam span length and $\mathrm{h}$ is the height of cross section. The maximum deformation at failure is $210 \mathrm{~mm}$ or the maximum deformation rate is $19 \mathrm{~mm} /$ minute for the analyzed beam. In this case, the failure is defined by the maximum deformation rate at 48 minutes from test and 42 minutes from FE analysis. FE analysis in LS-DYNA using parameters and material models from Eurocodes $[13,14]$ gives a little conservative fire resistance prediction.

\section{Structural analysis using shell element model}

This FE model is created using shell elements with Belytschko-Tsay formulation. Element size is $20 \mathrm{~mm}$ and three integration points are defined through the thickness. Temperature-dependent piecewise linear plastic material model MAT255 is used in this model, since MAT202 is not available for 3D shell element. The material properties and stress-strain relations are defined according to EN 1993-1-2. The temperature distribution and time history in the cross section are specified according to the output from 2D temperature analysis using keyword *Load_Thermal_Variable. Uniform temperatures are specified for flanges, and temperature gradient along the web height is defined by the temperatures in six web nodes. Pinned boundary condition is specified for the end nodes in the lower flange, with allowed axial movement in right end. Furthermore, lateral support in out of web plane direction is defined for both end sections. 
Fig. 5 illustrates the deformation response of the simply supported beam in fire at mid-span using shell elements. The deformation curve by FE analysis is able to capture the major behavior of the simply supported beam in fire. The fire resistance according to the failure criteria in Eq. 3 is around 42.5 minutes and the failure mode is lateraltorsional buckling of the beam. The fire resistance time is similar to the case using beam elements (42 minutes). Another case (FE-Shell-LR in Fig. 5) is analyzed with additional lateral supports in the loading points to simulate the possible lateral restraints by the actuators. The failure mode is plastic bending failure and lateral-torsional buckling (LTB) in mid-span of loading. The failure mode is the same as the test observations (Fig. 6). The deformation response using shell elements is closer to the test than beam element model since shell element models can better capture the lateral-torsional buckling failure mode. The corresponding fire resistance is 44 minutes, only slightly longer than the case without lateral restraints in loading points.

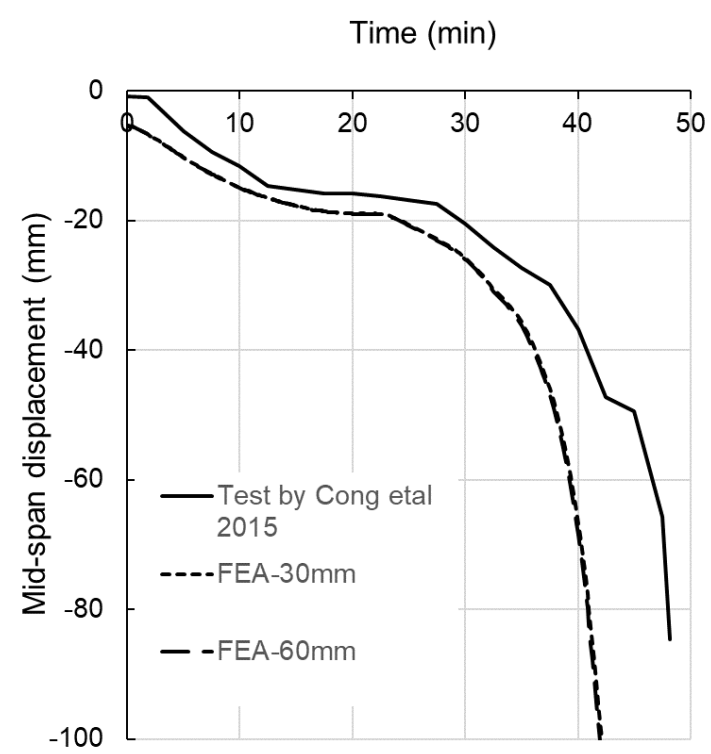

Figure 4. Mid-span displacement by beam element model.

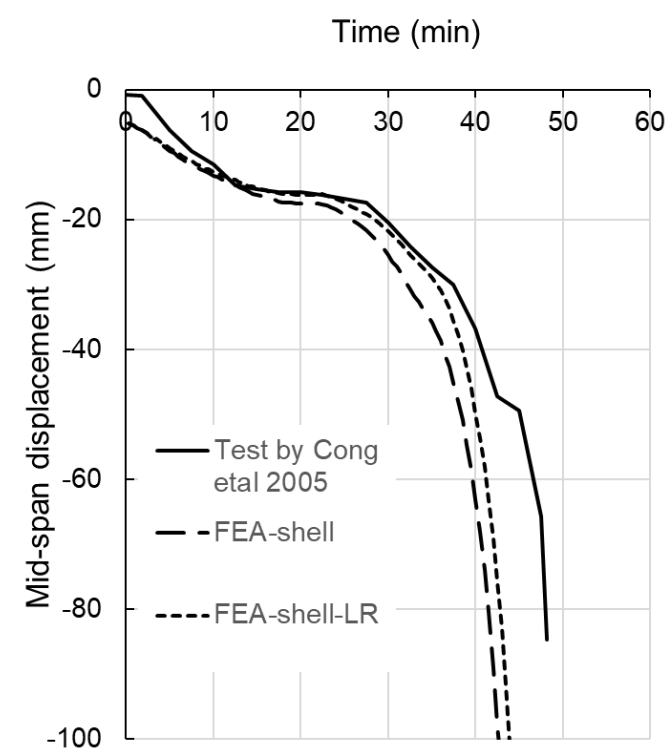

Figure 5. Mid-span displacement by shell element model.

\section{FE modeling of simple frame}

\section{Fire test description}

A natural fire test on a fully loaded, two-dimensional steel framework was carried out by British Steel [10]. The steel frame consists of a $4553 \mathrm{~mm}$ length of $406 \mathrm{x} 178 \mathrm{~mm} \mathrm{x}$ $54 \mathrm{~kg} / \mathrm{m}$ BS4360:1979 Grade 43A (equivalent S275) universal beam section bolted to two $3530 \mathrm{~mm}$ lengths of 203 x 203 x $52 \mathrm{~kg} / \mathrm{m}$ Grade 43A universal column section. Fig. 7 illustrates the principal features of the test frame. The beam was unprotected, but four 1200x $5550 \times 150 \mathrm{~mm}$ precast concrete slabs were attached to the top flange. No composite action was formed between concrete slabs and steel beam. The column was 
pinned at both lower and upper ends. The web was protected by autoclaved aerated concrete blocks. Six M20 Grade 8.8 bolts were used for beam-column connection. A maximum $552 \mathrm{kN}$ was applied on the top of each column. The test beam was loaded to $39.6 \mathrm{kN}$ at four positions along the span. The test loads were maintained as a constant during the fire tests. The gas temperature in the compartment is shown in Fig. 7(c). Further details on the testing can be found in $[10,11]$.

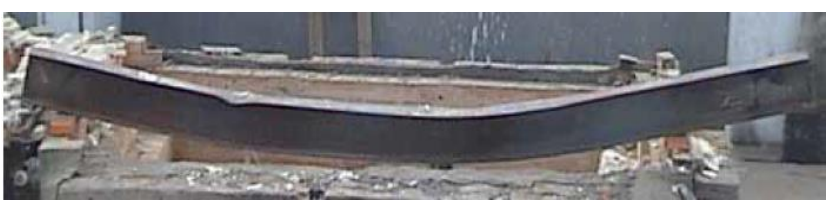

(a) Bending deformation from test

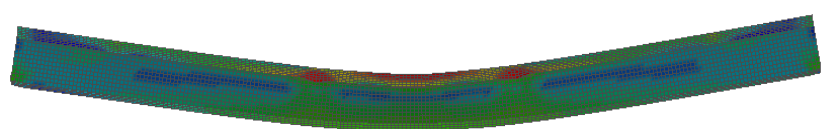

(c) Bending deformation from FE analysis

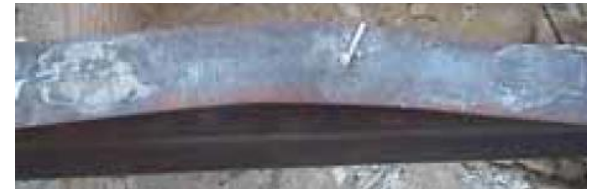

(b) LTB in central loading span

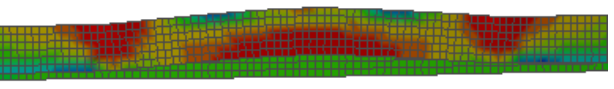

(d) LTB from FE analysis

Figure 6. Failure modes of testing observation and FE analysis.

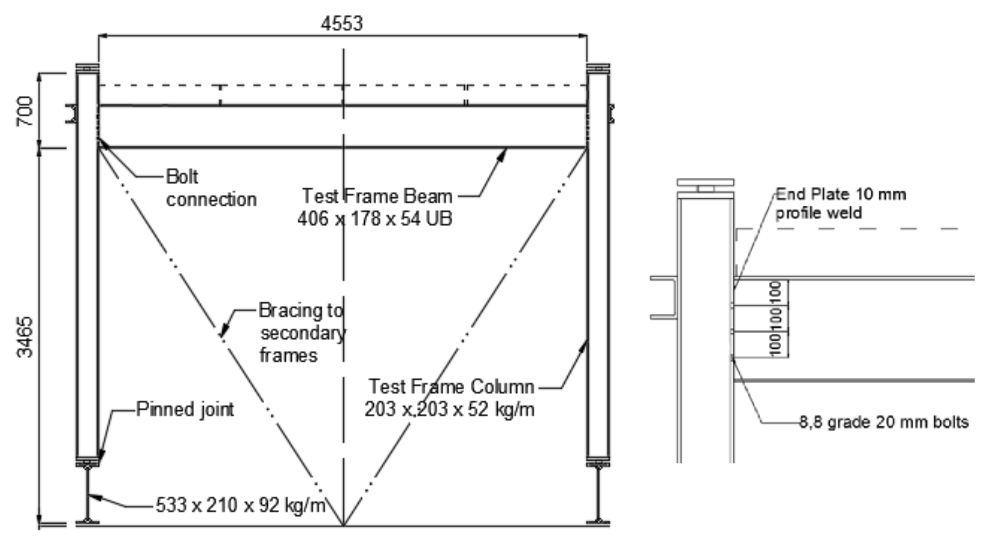

(a) Simple frame structure

(b) beam-column connection

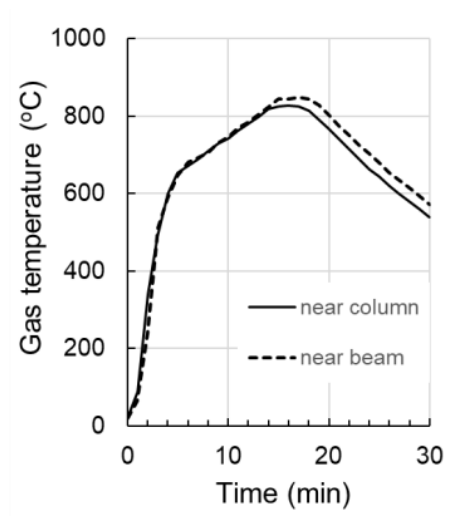

(c) gas temperatures

Figure 7. Structural layout of the test frame and fire curves.

\section{D-temperature analysis}

The mesh of the cross section of column is shown in Fig. 8(a). Due to the symmetry, only half of the cross section is meshed, and no heat transfer is defined in the symmetric boundary. Thermal properties of steel are defined according to EN 1994-1-2 [16]. The conductivity and specific heat of aerated light-weight concrete are defined according to [11]. The resultant emissivity coefficient is taken as 0.7 for left and lower sides facing the fire (Fig. 8a). The resultant emissivity coefficient is taken as 0.3 in the side facing the wall to account for some degree of radiative shadowing [11]. Convection coefficient 
$\alpha_{c}$ is taken as $25 \mathrm{~W} / \mathrm{m}^{2} \mathrm{~K}$ in all three sides. Aerated concrete block between column flanges and web is included in the model for temperature analysis only. Variable mesh size, with $6 \mathrm{~mm}$ in steel section, $3 \mathrm{~mm}$ in steel-concrete interface region and $9 \mathrm{~mm}$ in concrete block is used. A finer uniform mesh size of $3 \mathrm{~mm}$ is created as well and the result shows that the maximum difference for temperatures in steel section is less than $+3 \%$.

The mesh of the cross section of beam is shown in Fig. 8(b). Again, only half of the cross section is meshed due to the symmetry. The steel beam is facing the fire from all sides except the top face of upper flange, which is in contact with concrete slab. Concrete slab is included in the thermal model due to its influence on the temperature in upper flange of the steel beam. Thermal properties of steel and concrete are defined according to EN 1994-1-2 [16]. Emissivity factor of 0.7 is used for both steel beam and concrete. Convection coefficient of $25 \mathrm{~W} / \mathrm{m}^{2} \mathrm{~K}$ is used for steel beam and lower side of concrete slab, and that of $9 \mathrm{~W} / \mathrm{m}^{2} \mathrm{~K}$ is used for the unexposed side of concrete slab.

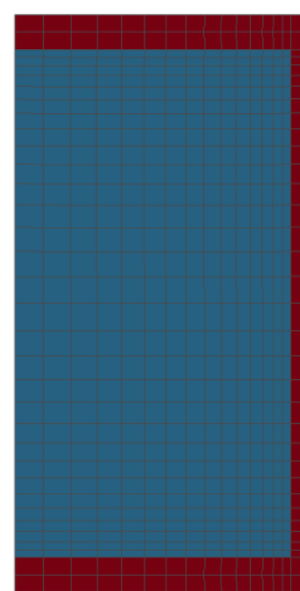

(a) column

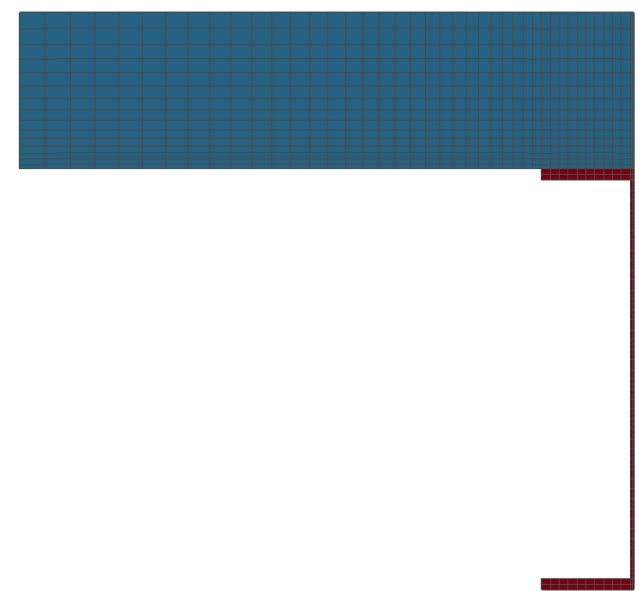

(b) beam

Figure 8. FE meshes of column and beam cross sections.

Fig. 9 shows the comparison of temperature histories for steel column and beam between the 2D FE analyses and measurements by thermal couples. It can be seen that, for steel column, the maximum differences are $40{ }^{\circ} \mathrm{C}$ at 22 minutes $(7 \%)$ in the flange facing the fire, $30{ }^{\circ} \mathrm{C}$ at 25 minutes $(5 \%)$ in the flange facing wall, and $9{ }^{\circ} \mathrm{C}$ at 23 minutes (3\%) at web, respectively. For steel beam, the maximum differences are $60{ }^{\circ} \mathrm{C}$ at 23 minutes $(11 \%)$ in upper flange in contact with concrete, and $25{ }^{\circ} \mathrm{C}$ at 20 minutes (3\%) in lower flange, respectively. In Fig. 9(b), there is no measurement data available for web central point, so only FE result is shown. The agreement between FE analyses and measurements is fairly good. 


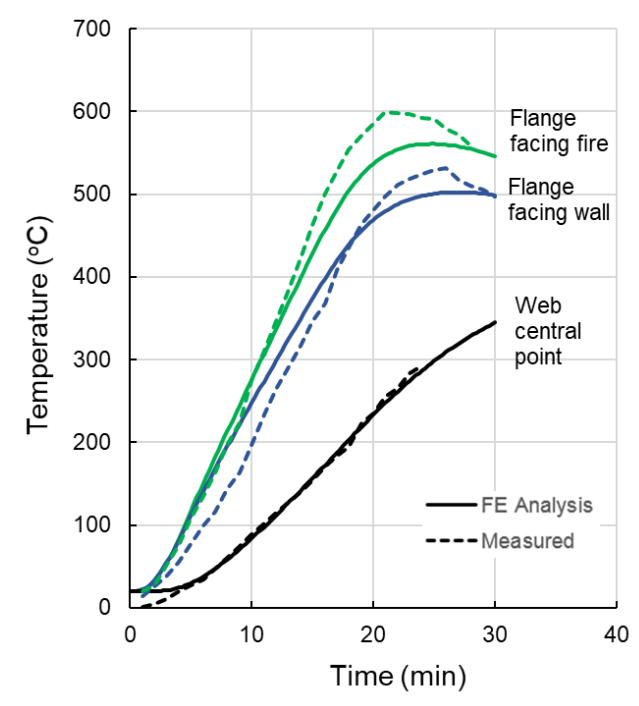

(a) column

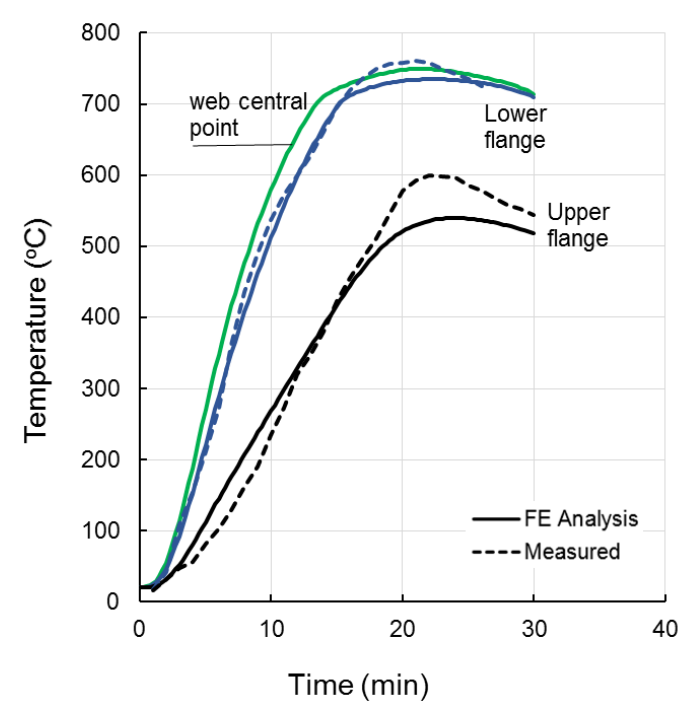

(b) beam

Figure 9. Temperature history of steel column and beam.

\section{Structural analysis using beam element model}

Hughes-Liu beam element with user defined cross section integration is used in the modeling of simple frame. In total there are 39 integration points in the I-shape cross section by defining refinement factor $\mathrm{k}$ as 5 in LS-DYNA. Temperature-dependent material model MAT202 was used, but with redefined thermal expansion coefficient (CTE) and stress-strain data according to EN1993-1-2. Non-uniform temperature distribution in the cross sections of beam and column is defined by using *Load_Thermal_Variable_Beam_Set keyword. Thermal loading histories for beam and column are defined in the cross-section coordinates. For cross section of column, in total fifteen temperature histories are defined, in which five data points in flange facing the fire and flange facing the wall, respectively, and five data points along the web. For cross section of beam, uniform temperature is assumed in flanges, and six data points are specified in the web. These temperature histories are calculated from 2D temperature analyses.

Due to the symmetry, only half of the structure is modelled. The FE model is illustrated in Fig. 10(a). Pinned boundary condition is defined for the lower end of the column, and symmetric boundary is defined in the right end of the beam. A discrete beam element is used in the position $100 \mathrm{~mm}$ above the beam-column connection to simulate the restraint from the secondary support frame. The spring constant is 6700 $\mathrm{kN} / \mathrm{m}$ and the yielding force of the spring is $68 \mathrm{kN}$ (MAT68) according to [11].

The loading and heating process are the same as the case for simply supported beam. The ratio of kinetic energy to internal energy is in the level of $10^{-5}$, which is very insignificant. 


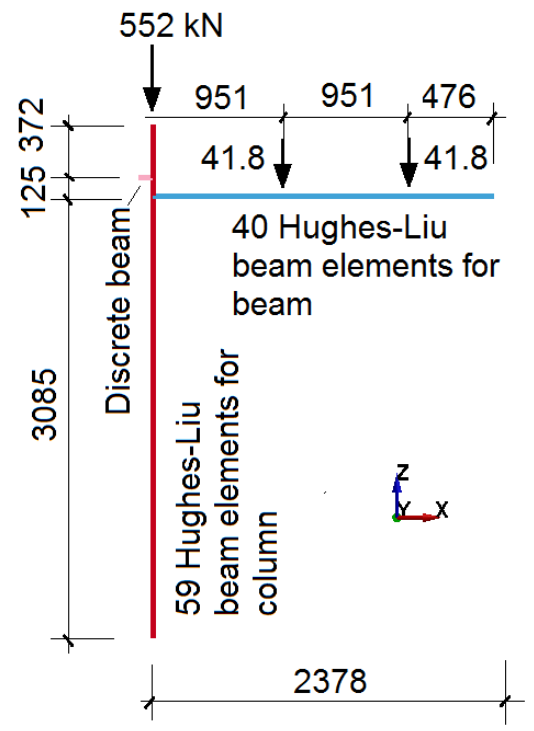

(a) beam element model

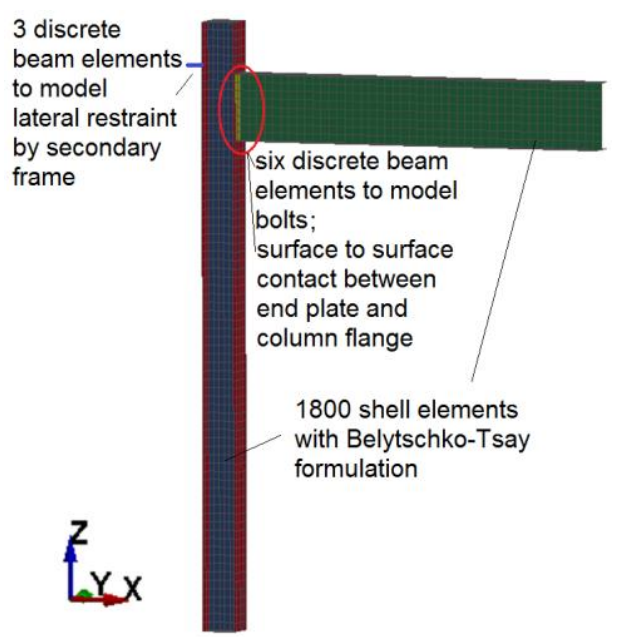

(b) shell element model

Figure 10. FE models for simple frame.

The mid-span displacement history of steel beam, deformation of steel column and axial force in the beam are examined in more detail in this analysis. Fig. 11(a) shows the mid-span history of steel beam. The general deformation behavior is close to each other between the FE analyses and testing measurement. However, the time to failure (run away) varies a lot. FE analyses show that the fire resistance time of steel frame depends on the yield strength of the steel. The actual yield strength of steel used in this frame was not measured, hence the case with minimum yield strength of $275 \mathrm{MPa}$ and the case with possible yield strength of $350 \mathrm{MPa}$ [15] were analyzed. The analyzed fire resistance time is 14 minutes for $\mathrm{f}_{\mathrm{y}}=275 \mathrm{MPa}$, and 16 minutes for $\mathrm{f}_{\mathrm{y}}=350 \mathrm{MPa}$, while the tested fire resistance is 19 minutes. The fire analysis results by another FE software CEFICOSS in [11] using beam elements and yield strength $\mathrm{f}_{\mathrm{y}}=350 \mathrm{MPa}$ are included in the comparison. Further details on FE analysis by CEFICOSS can be found in [11]. The analyzed fire resistance time by CEFICOSS is 14 minutes for $\mathrm{f}_{\mathrm{y}}=275 \mathrm{MPa}$, and 17.5 minutes for $\mathrm{f}_{\mathrm{y}}=350 \mathrm{MPa}$. LS-DYNA gives conservative prediction in fire resistance time in this analysis.

Fig. 11(b) shows the predicted axial compression forces by LS-DYNA and CEFICOSS for the beam for yield strength of $350 \mathrm{MPa}$. The maximum axial compression force is $100 \mathrm{kN}$ by LS-DYNA and $124 \mathrm{kN}$ by CEFICOSS. Since the time to failure is different from test and FE analysis, an equivalence method is used for the comparison of lateral deformation of column. The measured vertical displacement in the beam mid-span is around $36.5 \mathrm{~mm}$ at 16 minutes, then the time to reach same vertical displacement in beam is 14 minutes (case $\mathrm{f}_{\mathrm{y}}=350 \mathrm{MPa}$ ). Then the lateral (horizontal) deformation of column at 14 minutes from FE analysis is compared with that at 16 minutes from test measurement (Table 1). From Table 1, it can be seen that the differences vary from $-53 \%$ to $+5.5 \%$ for beam element model, and $-60 \%$ to $-14 \%$ for shell element model. This is due to the fact that the lateral displacements in the column is relatively small, and it is sensitive to the boundary conditions in the ends of column. 
The actual pinned joint in the lower end of column in the test may not work exactly the same as pinned boundary definition in the FE models.

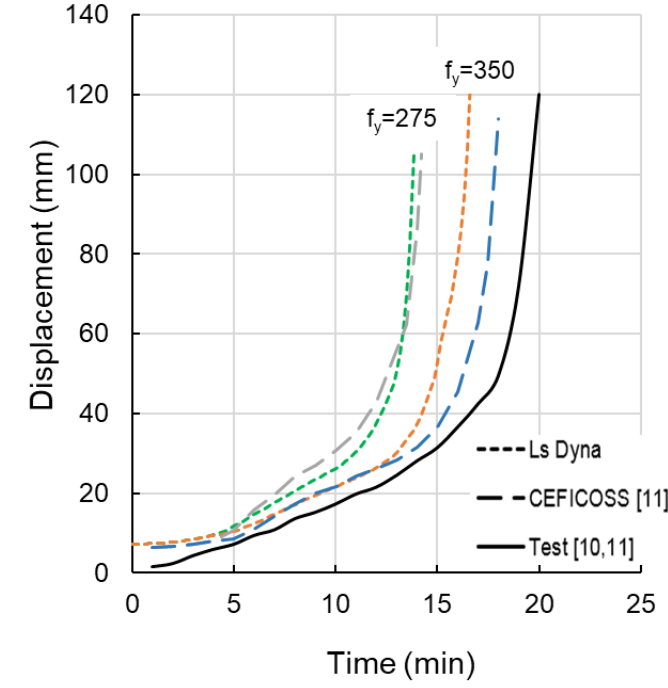

(a) Vertical mid-span displacement of beam

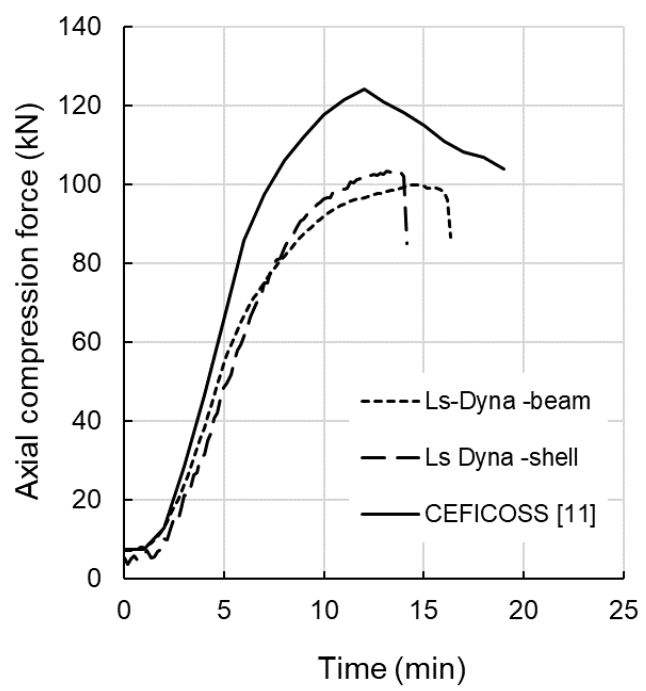

(b) Axial compression forces of beam

Figure 11. Structural response of frame using beam element model in fire.

Table 1. Lateral displacements of column along the height.

\begin{tabular}{|c|c|c|c|}
\hline \multirow[t]{2}{*}{ Lateral Displacement (mm) } & \multicolumn{3}{|c|}{$\begin{array}{l}\text { Distance along column height from lower end } \\
\text { (mm) }\end{array}$} \\
\hline & 147 & 1477 & 2847 \\
\hline $\begin{array}{l}\text { Lateral displacement by FE using beam } \\
\text { model at } 14 \min (\mathrm{mm})\end{array}$ & $\begin{array}{c}4.48 \\
(-53 \%)\end{array}$ & $\begin{array}{c}22.2 \\
(+5.5 \%)\end{array}$ & $\begin{array}{c}15.2 \\
(-29 \%)\end{array}$ \\
\hline $\begin{array}{l}\text { Lateral displacement by FE using shell } \\
\text { model at } 11 \mathrm{~min}(\mathrm{~mm})\end{array}$ & $\begin{array}{c}3.84 \\
(-60 \%)\end{array}$ & $\begin{array}{c}17.5 \\
(-17 \%)\end{array}$ & $\begin{array}{c}18.5 \\
(-14 \%)\end{array}$ \\
\hline Lateral displacement by test at $16 \mathrm{~min}(\mathrm{~mm})$ & 9.47 & 21.0 & 21.5 \\
\hline
\end{tabular}

Note: The percentage value in the parenthesis indicates the difference from reported testing measurement result.

\section{Structural analysis using shell element model}

This FE model was created using shell elements with Belytschko-Tsay formulation (Fig. 10(b)). Hourglass control is used with hourglass control type IHQ = 5 (FlanaganBelytschko stiffness form) and hourglass coefficient $\mathrm{QM}=0.1$. Element size is $50 \mathrm{~mm}$ and three integration points are defined through the thickness. In order to avoid local crush failure in the webs of lower and upper ends of columns in fire under the axial load, the thickness of end plates is increased to $50 \mathrm{~mm}$ in the analysis. A refined model 
with $20 \mathrm{~mm}$ mesh size was analyzed and the deformation history of at mid-span of beam is almost identical (max difference around 1\%). This proves that the used mesh size is acceptable. Temperature-dependent piecewise linear plastic material model MAT255 is used and mechanical properties are specified according to EN1993-1-2. Beam is supported laterally out of the web plane in four loading positions on top flange to model the lateral supports by concrete slabs.

Six discrete beam elements are used to model the bolt connection between column and beam. The translational spring stiffness of $2 \mathrm{E} 6 \mathrm{kN} / \mathrm{m}$ is specified for $\mathrm{x}-, \mathrm{y}-$ and $\mathrm{z}-$ directions and the rotational spring stiffness of $2 \mathrm{E} 4 \mathrm{kN} . \mathrm{m} / \mathrm{rad}$ is specified for rotational directions. Automatic surface to surface contact is defined between the end plate of steel beam and the inner flange of column facing the fire, to simulate the compression contact in the lower part of beam end plate against column flange.

Fig. 12 shows the vertical deformation response of beam at mid-span during fire. The predicted fire resistance time is 12.5 minutes when yield strength is $275 \mathrm{MPa}$ and 13.7 minutes when yield strength is $350 \mathrm{MPa}$. The predicted fire resistance time is less than the corresponding beam element model. Table 2 summarizes the fire resistance time by FE using beam and shell models, and compares the predicted fire resistance time with the test. The failure criteria are defined in the same way as simply supported beam case, i.e. the maximum deformation of $\mathrm{L} / 20$ or deformation rate according to Eq. 3 , whichever occurs earlier. It can be seen that fire resistances by FE analyses are smaller than the test, and prediction using beam elements gives closer fire resistance to the test.

From Fig. 12 it can also be seen that the effect of steel grade on deformation response at mid-span of steel beam is not as big as the case using beam elements. This is due to that the failure modes using shell elements are first lateral-torsional buckling of steel beam and then the collapse of beam web. This structural behavior is not simulated by beam elements model. However, it is not clear that how the concrete slabs and additional support system interact with steel beam in the fire test. Considerable twisting of steel beam was observed after the test [10].

Axial compression force developed in the beam is shown in Fig. 10(b). The axial force is similar to the FE prediction using beam element model. The maximum predicted compression force is $102 \mathrm{kN}$. Lateral displacement along the column height at 11 minutes is shown in Table 1. The corresponding vertical displacement at beam midspan in shell model is $36.5 \mathrm{~mm}$ at 11 minutes, corresponding to the same displacement at 16 minutes at test. The predicted lateral deformation in column is closer to the test measurement in the locations away from lower column end than that near lower end.

\section{FE modeling of restrained column}

\section{Fire test description}

Ali and O'Connor [21] tested both axially and rotationally restrained steel column under fire. The steel column is $127 \mathrm{x} 76 \mathrm{UB} 13$ and grade is S275. Column length is $1800 \mathrm{~mm}$. Both ends of the column were welded with two 200x750x40 mm steel plates. These two plates provide rotational restraints in both ends of column. The ends of the top and bottom plates were connected with the rig using two light bolts in each end, so that the 
edge restraints can be considered as simply supported [21]. The imposed stiffness of axial restraint is around $57 \mathrm{kN} / \mathrm{mm}$ [21]. On the top of the column, an axial load of 205 $\mathrm{kN}$ is applied. The heated length of column is around $1750 \mathrm{~mm}$, and both top and bottom plates are located outside of the furnace. The column temperatures in different locations are measured using thermocouples. The average column temperature is shown

Table 2. Predicted fire resistance time versus fire test.

\begin{tabular}{l|c|c}
\hline & $\mathrm{f}_{\mathrm{y}}=275 \mathrm{MPa}$ & $\mathrm{f}_{\mathrm{y}}=350 \mathrm{MPa}$ \\
\hline Predicted time to failure by beam model (min) & 14.0 & 16.0 \\
\hline Predicted time to failure by shell model (min) & 12.5 & 13.7 \\
\hline $\begin{array}{l}\text { Predicted time to failure by beam model - } \\
\text { CEFICOSS [11] (min) }\end{array}$ & 14.0 & 17.5 \\
\hline Time to failure by fire test (min) & 19.0 & 19.0 \\
\hline
\end{tabular}

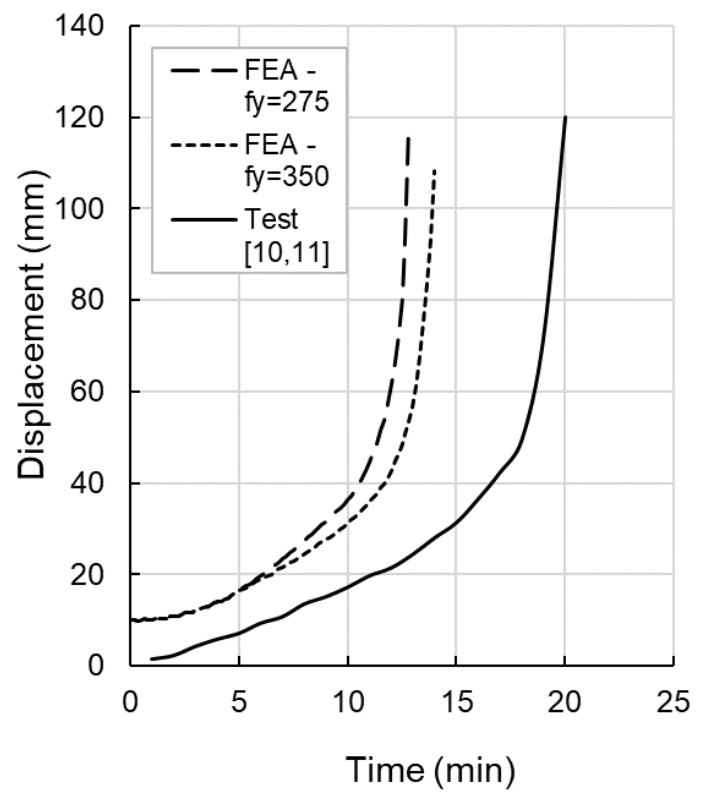

Figure 12. Vertical displacement of beam in fire using shell element model.

in Fig. 14. This average column temperature curve will be used in the structural analysis and temperature analysis of steel column is not necessary in this case. Further details on the tests can be seen in [21].

From [21], the axial restraints work in a way so that it provides axial restraint when column expands vertically and is subjected to compression force. After material softening and the column buckling occur, the axial force decreases to zero and the system will not provide further restraint in axial direction. In another word, the axial 
restraint only works when thermal expansion of column causes additional compression force in the system.

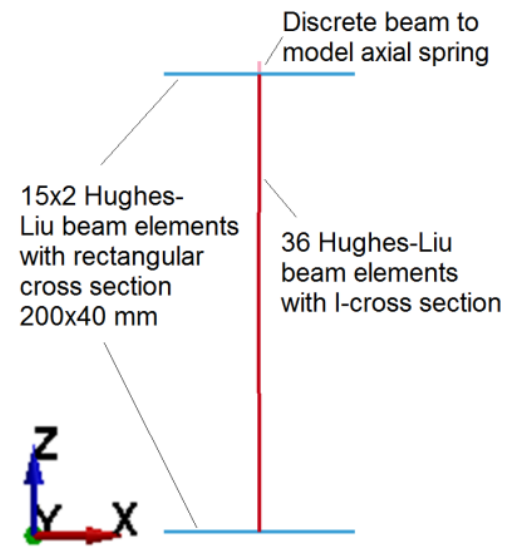

(a) beam model

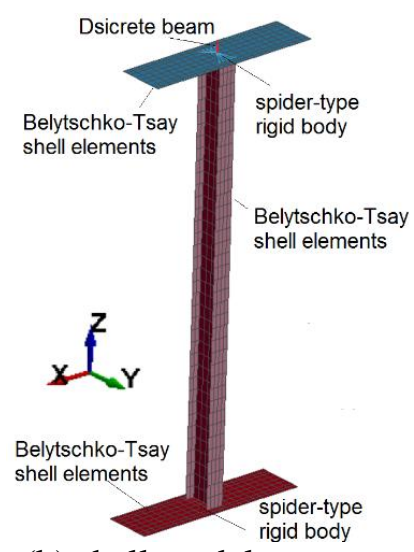

(b) shell model

Figure 13. FE models using beam and shell elements.

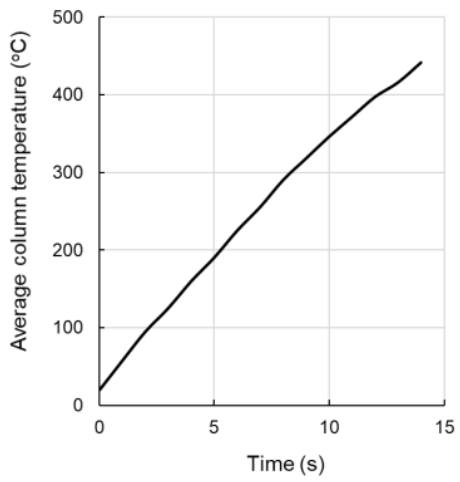

Fig. 14. Average column temperature versus time.

\section{FE analysis using beam element model}

Hughes-Liu beam elements with user-defined integration in the cross section were used to model the steel column and plates. Based on the previous two analyses, the element size of $50 \mathrm{~mm}$ is suitable for this structure. Therefore around 36 elements are used in the column and 15 elements in each plate. A discrete beam is used on the top end of steel column to model the axial spring restraint provided by vertical support system. A simple calculation using simply supported beam model is used to calculate the stiffness of top plate under vertical force in the middle of the beam span. Result shows that the stiffness of axial restraint by top plate is $24.3 \mathrm{kN} / \mathrm{mm}$ in this model. Therefore, the axial stiffness of the discrete beam (Fig. 13) is $32.7 \mathrm{kN} / \mathrm{mm}$. By this the total axial stiffness provided by the structural system in this model is $57 \mathrm{kN} / \mathrm{mm}$. In order to avoid the axial restraint during the loading phase (before furnace heating), *Boundary_SPC_Birth_Death is used in defining the boundary conditions of both ends of top plate and upper node of discrete beam. Fixed boundary condition in vertical direction is imposed only after the initial static loading of $205 \mathrm{kN}$ is applied. This is achieved by defining the starting time of the boundary condition (Birth Time). During the heating process, the column will expand in length direction, the axial restraints induce additional compression force in the column and the total force is greater than initial loading. After buckling and material softening, the force in column will decrease and reach $205 \mathrm{kN}$ compression force again. This time is set as end of the vertical restraints (Death Time), since the column lose stability in the testing and otherwise, after that the axial force of restraints would become tensile.

The geometrical imperfection of L/1000 is applied to the mid-height of steel column in the $\mathrm{x}$-direction (around minor-axis) and the shape of imperfection is approximately sinusoidal. The length range $1750 \mathrm{~mm}$ of steel column is heated using the measured average column temperature curve (Fig. 14). 
The axial force in the column, the axial displacement in the top end of column and the lateral displacement at mid-span are studied and the analysis results are compared with test measurement. The results were presented in the form of responses versus average column temperature (Fig. 15). The actual yield strength of tested column was not measured in the test. According to studies in $[11,15,22]$, the actual yield strength of S275 could be between 275-400 MPa. Therefore, two cases with yield strengths of 275 and $350 \mathrm{MPa}$ were analyzed. It can be seen that yield strength has significant effect on the structural response of the steel column and the case with yield strength of $350 \mathrm{MPa}$ gives better prediction in axial forces and lateral displacement at mid-span. The development of axial force in the heated column shows that both the ascending phase and peak value are close between testing result and FE prediction. The declination of generated axial force in steel column by FE prediction is a little faster than testing measurement. From the analysis, the applied axial load of $205 \mathrm{kN}$ causes $1.14 \mathrm{~mm}$ axial compression displacement before heating. It is assumed that the axial displacement measurement (zero value) was started after loading and before heating. Therefore, the total axial expansion by FE analysis is $3.05 \mathrm{~mm}$ and that by testing is stated as $2.0 \mathrm{~mm}$ for yield strength of $350 \mathrm{MPa}$ case. From Fig. 15(c) it can be seen that the development of lateral displacement at mid-span of steel column is close between testing and FEA for yield strength of $350 \mathrm{MPa}$ case. The buckling temperature is $208{ }^{\circ} \mathrm{C}$ for FEA (yield strength $350 \mathrm{MPa}$ ) and $225{ }^{\circ} \mathrm{C}$ for testing measurement. The failure temperature (run away) is $365^{\circ} \mathrm{C}$ for $\mathrm{FE}$ prediction and $425^{\circ} \mathrm{C}$ for testing measurement.

\section{FE analysis using shell element model}

The FE model using shell elements is shown in Fig. 13(b). This FE model was created using shell elements with Belytschko-Tsay formulation. Hourglass control is used with hourglass control type IHQ $=5$ (Flanagan-Belytschko stiffness form) and hourglass coefficient $\mathrm{QM}=0.1$. Element size is $50 \mathrm{~mm}$ and five integration points are defined through the thickness. In the bottom plate, the simply supported boundary conditions are defined for left edge and right edge. In the top plate, similar boundaries are defined but with birth time at 2 seconds (after $205 \mathrm{kN}$ axial loading application is completed). The death time is defined based on first run, i.e. the time corresponding to axial load that reaches $205 \mathrm{kN}$ compressive force again during heating process. At this point, the axial restraint starts to be in tension otherwise and the restraint is released in test.

In both ends of steel column, two spider-type rigid bodies are defined for boundary conditions and axial loading application. *Constrained_Nodal_Rigid_Body is used to define the rigid bodies. Boundary conditions are specified in the master nodes of the rigid bodies. In the lower end, hinged boundary condition with restrained z-axis rotation is defined, and in the upper end, same hinged boundary and restrained $\mathrm{z}$-axis rotation but with free movement in z-direction (vertical). Discrete beam element is used to model the axial restraints and the definition of boundary for top node is same as described in above beam element model.

The loading and heating procedure are the same as in previous analyses. The axial force in the column, the axial displacement in the top end of column and the lateral displacement at mid-span are studied and the analysis results are compared with test measurement (Fig. 16). Table 3 summarizes the major analysis results and compares 
with test measurement. It can be seen that the FE analysis results using beam and shell element model are very close to each other. The analysis results using yield strength of $350 \mathrm{MPa}$ are closer to the test results in axial force and lateral displacement, but larger difference for axial displacement. The difference could be narrowed down when the exact material strength is known and the detailed configuration of axial restraint and measurement setting in the test are known.

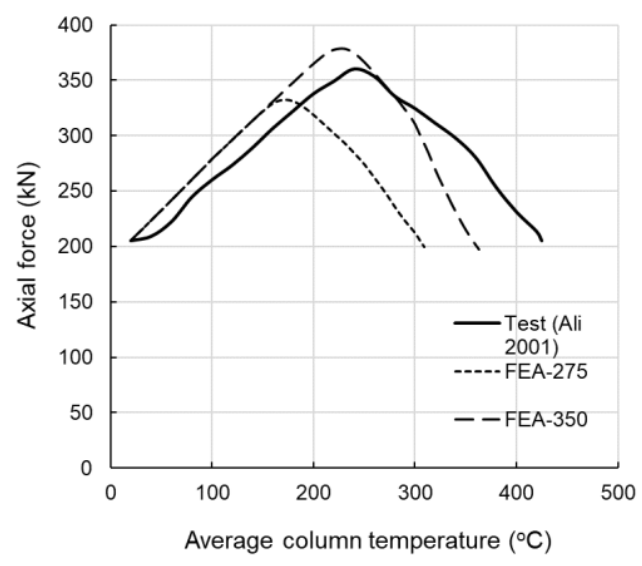

(a) axial forces

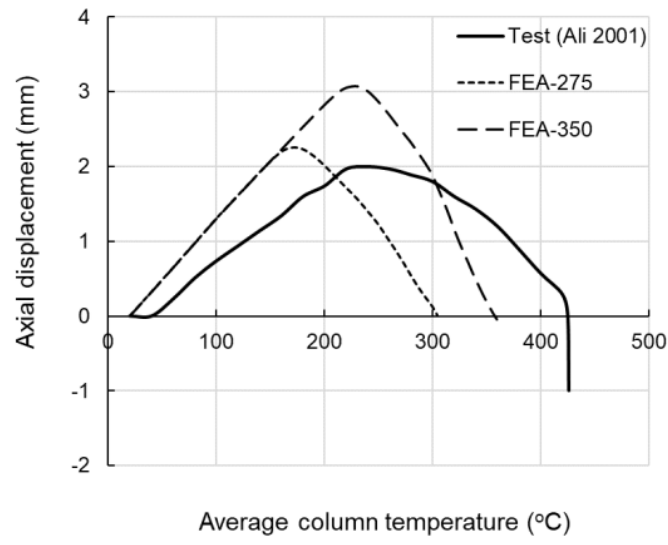

(b) axial displacement

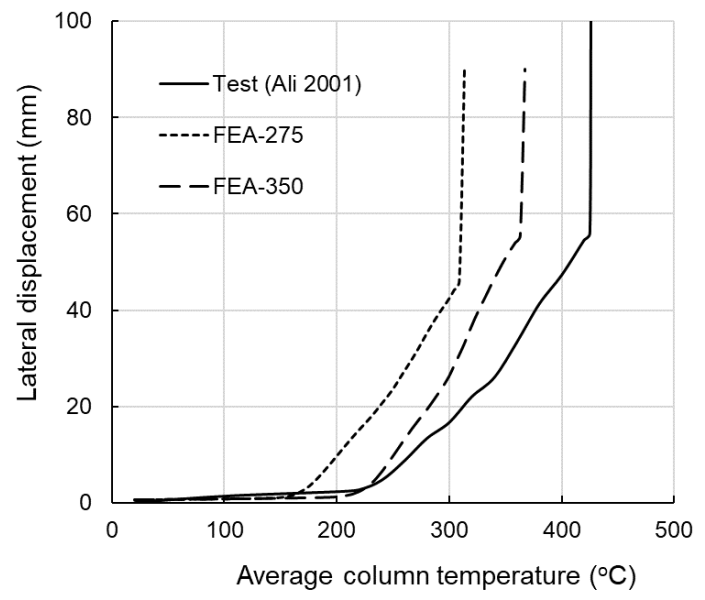

(c) lateral displacement at mid-span

Figure 15. Structural responses of steel column during fire using beam element model.

\section{Conclusions}

Three fire tests, with a simply supported steel beam, a simple steel frame and a restrained column were modelled using LS-DYNA from 2D temperature analysis to structural response analysis. The implicit scheme was used for 2D temperature analysis since it is efficient. The structural fire analysis was carried out using explicit solver since it involves large deformation, high-nonlinearity of temperature-dependent material properties, and possible contact iterations. The thermal loadings of steel components 
were exerted using 2D temperature analysis results. Since the actual heating process during fire is long and it varies from minutes to a few hours, the analysis duration must be scaled down to obtain reasonable computational efficiency. The structural response and ratio of kinematic to internal energy are the major parameters showing the validity of scaling. In the analyses carried out in this paper, a scaling factor of 100 is proved to be suitable for the studied cases. A loading time of 2 seconds from zero to desired load level were used in the analyses. This corresponding to an actual loading time of 3.3 minutes.

The deformation response at mid-span of beam, lateral displacement of column, axial forces due to thermal expansion and restraints, and fire resistance time were compared with the test measurement and previous analysis using CEFICOSS from literature. In general, the agreement is fairly good for temperature histories. The maximum temperature difference for simply supported beam case is $85{ }^{\circ} \mathrm{C}$ in top flange at 15 minutes and $60{ }^{\circ} \mathrm{C}$ in top flange of beam at 23 minutes for simple frame case. LSDYNA explicit solver is able to predict the structural responses well in deformation response and axial force due to restraints. It gives smaller fire resistance time when the fire parameters and material properties were taken from Eurocodes. For all three fire tests, the prediction by LS-DYNA is closer to the testing measurement by Hughes-Liu beam element model for yield strength of $350 \mathrm{MPa}$ case, except a larger difference in axial displacement of restrained steel column. For simply supported beam case and restrained steel column case, FE prediction using Belytschko-Tsay shell element is also close to testing result, except larger difference in axial displacement for restrained column case for yield strength $350 \mathrm{MPa}$. For simple frame case, FE prediction on the fire resistance time (time to failure) using shell element has larger difference from the test measurement.

The following improvements could be done in the future research, in order to narrow the differences between FE modeling results and fire tests:

1) For standard furnace fire test, the emissivity and convection coefficients by Eurocode give relatively higher temperature prediction in steel beam. A calibration work could be carried out in future to give more accurate guideline in this aspect.

2) For structural fire analysis, the strength of steel material has significant effect on the fire resistance prediction and structural responses. Hence, in the future fire tests, the strength properties of used steel materials should be carefully measured and reported.

3) Generally speaking, beam element models give similar results of structural responses in fire as shell element models., unless local failures (local buckling and crushing) and lateral-torsional buckling are important. Shell element model demands more computational resources than beam element model. In LSDYNA, proper hourglass control is necessary for reduced integration shell element. The sensitivity of controlling parameters for hourglass could be studied further and guideline could be given.

4) For simple frame case, further study could be made in future to investigate the effect of different modeling methods for column end supports. The actual support in lower end of column in the test may allow certain degree of lateral 
movement. For axial displacement in restrained column case, the axial displacement is only $2 \mathrm{~mm}$, therefore the timing when displacement transducer starts the measurement is critical (i.e. before or after vertical loading). This is not reported in the literature.

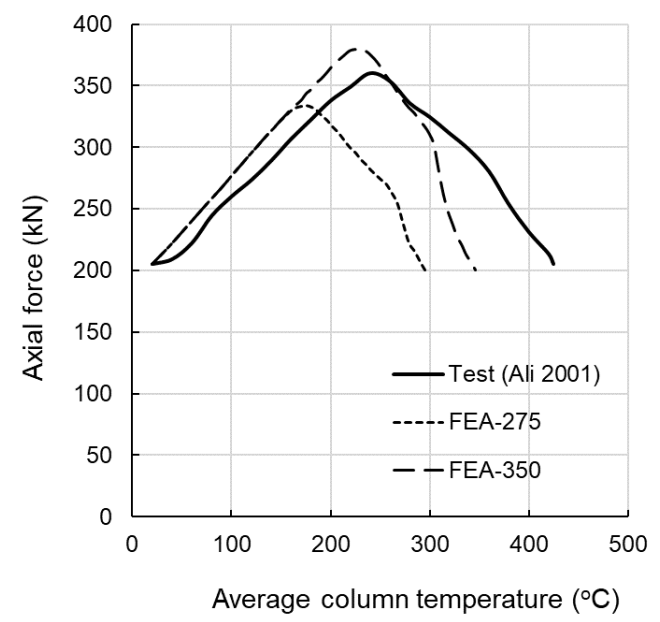

(a) axial force

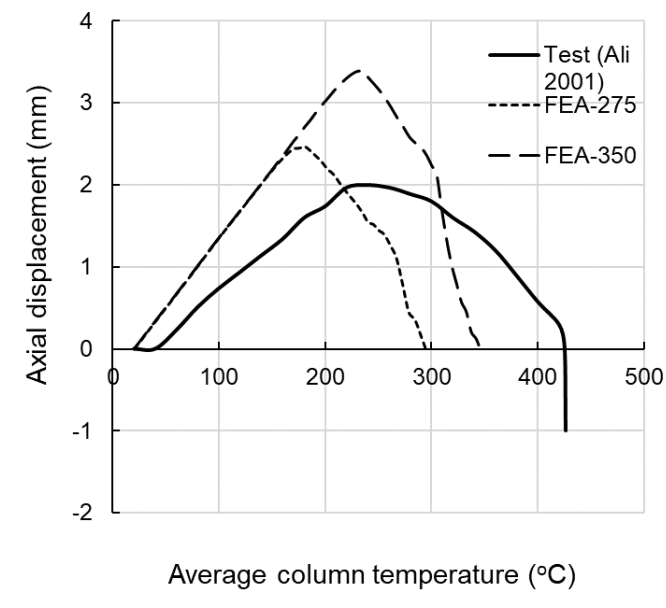

(b) axial displacement

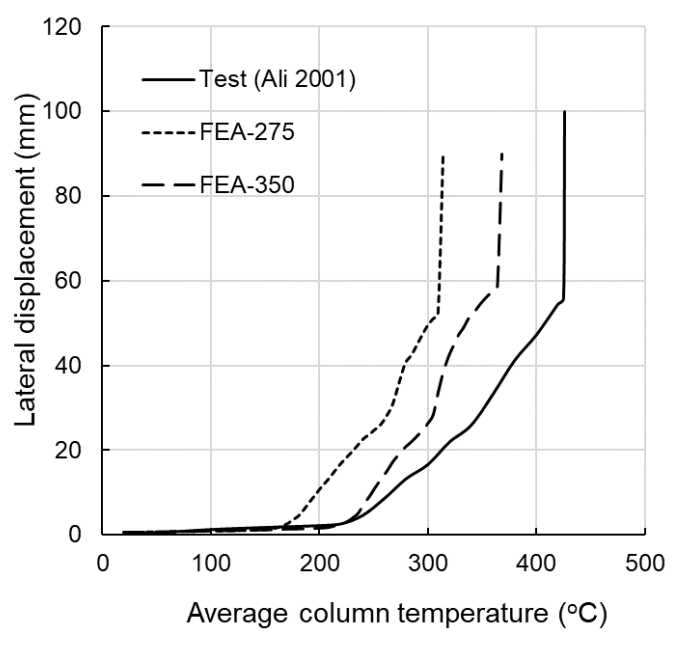

(c) lateral displacement at mid-span

Figure 16. Structural responses of steel column during fire using shell element model. 
Table 3. Summary of FE analysis results and comparison with test.

\begin{tabular}{|c|c|c|c|c|c|c|c|c|c|}
\hline \multirow{2}{*}{\multicolumn{2}{|c|}{ FE models }} & \multicolumn{2}{|c|}{$\begin{array}{l}\text { Max. axial } \\
\text { force }(\mathrm{kN})\end{array}$} & \multicolumn{2}{|c|}{$\begin{array}{l}\text { Max. axial } \\
\text { displacement } \\
(\mathrm{mm})\end{array}$} & \multicolumn{2}{|c|}{$\begin{array}{l}\text { Temperature } \\
\text { corresponding to } \\
\text { max. force and } \\
\text { displ. }\left({ }^{\circ} \mathrm{C}\right)\end{array}$} & \multicolumn{2}{|c|}{$\begin{array}{l}\text { Buckling } \\
\text { temperature }\left({ }^{\circ} \mathrm{C}\right)\end{array}$} \\
\hline & & FEA & Test & FEA & Test & FEA & Test & FEA & Test \\
\hline \multirow[t]{2}{*}{ Beam } & $275 \mathrm{MPa}$ & $\begin{array}{l}335 \\
(-7 \%)\end{array}$ & \multirow{4}{*}{360} & $\begin{array}{l}2.31 \\
(+15 \%)\end{array}$ & \multirow{4}{*}{2.0} & $\begin{array}{l}165 \\
(-31 \%)\end{array}$ & \multirow{4}{*}{240} & $\begin{array}{l}160 \\
(-29 \%)\end{array}$ & \multirow{4}{*}{225} \\
\hline & $350 \mathrm{MPa}$ & $\begin{array}{l}377 \\
(+5 \%)\end{array}$ & & $\begin{array}{l}3.05 \\
(+52 \%)\end{array}$ & & $\begin{array}{l}236 \\
(-2 \%)\end{array}$ & & $\begin{array}{l}208 \\
(-8 \%)\end{array}$ & \\
\hline \multirow[t]{2}{*}{ Shell } & $275 \mathrm{MPa}$ & $\begin{array}{l}338 \\
(-6 \%)\end{array}$ & & $\begin{array}{l}2.43 \\
(+22 \%)\end{array}$ & & $\begin{array}{l}170 \\
(+29 \%)\end{array}$ & & $\begin{array}{l}165 \\
(-27 \%)\end{array}$ & \\
\hline & $350 \mathrm{MPa}$ & $\begin{array}{l}379 \\
(+5 \%)\end{array}$ & & $\begin{array}{l}3.30 \\
(+65 \%)\end{array}$ & & $\begin{array}{l}231 \\
(-4 \%)\end{array}$ & & $\begin{array}{l}214 \\
(-5 \%)\end{array}$ & \\
\hline
\end{tabular}

\section{References}

[1] Johnson P.F. (1998). International developments in fire engineering of steel structures. Journal of Constructional Steel Research, 46: 1-3. https://doi.org/10.1016/s0143-974x(98)00113-8

[2] SCI (1991). Structural fire engineering: Investigation of broadgate phase 8 fire. Steel Construction Institute.

[3] Baily C.G., Lennon T., Moore D.B. (1999). The behavior of full-scale steelframed building subjected to compartment fires. The Structural Engineer, 77 (8): $15-21$.

[4] Ma Z. and Mäkeläinen P. (2006). Structural behavior of composite slim floor frames in fire conditions. Journal of constructional steel research, 62(12): 12821289. https://doi.org/10.1016/j.jcsr.2006.04.026

[5] Kodur V.K.R., Garlock M., Iwankiw N. (2012). Structures in fire: state-of-the-art, research and training needs. Fire Technology, 48: 825-839.

https://doi.org/10.1007/s10694-011-0247-4

[6] Knobloch M. (2017). Structural fire design - developments in research and assessment of fire in steel and composite structures. Eurosteel 2017, September 13-15. Copengagen, Denmark. https://doi.org/10.1002/cepa.44

[7] Paik J.K., Czujko J., Kim J.H., Park S.I., Islam M.S., Lee D.H. (2015). A new procedure for the nonlinear structural response analysis of offshore installations in fires. In Transactions - Society of Naval Architects and Marine Engineers 121: 224-250. 
[8] Rackauskaite E., Kotsovinos P., Rein G. (2017). Model parameter sensitivity and benchmarking of the explicit dynamic solver of LS-DYNA for structural analysis in case of fire. Fire Safety Journal, 90: 123-138.

https://doi.org/10.1016/j.firesaf.2017.03.002

[9] Kwaśniewski L., Ali F., Balcerzak M., (2013). Coupled structural-thermal calculations for restrained steel columns in fire", Journal of Structural Fire Engineering, 4 (1), pp.59-70, https://doi.org/10.1260/2040-2317.4.1.59

[10] Cooke G.M.E., Latham D.J. (1987). The inherent fire resistance of a loaded steel framework. Steel Construction Today, 1: 49-58.

[11] Franssen J.M., Cooke G.M.E., Latham D.J. (1995). Numerical simulation of a full scale fire test on a loaded steel framework. Journal of Constructional Steel Research, 35: 377-408. https://doi.org/10.1016/0143-974x(95)00010-s

[12] Li, G.Q., Wang, P.G. (2013). Advanced analysis and design of fire safety of steel structures. Zhejiang University Press, China.

[13] EN1991-1-2 (2003). Eurocode 1: Actions on structures. Part 1-2: General actions. Actions on structures exposed to fire. European Committee for Standardization (CEN).

[14] EN1993-1-2 (2005). Eurocode 3: Design of steel structures - Part 1-2: General rules - Structural fire design. European Committee for Standardization (CEN).

[15] Cong, S., Liang, S., Dong, Y. (2005). Experimental investigation of behavior of simple supported steel beams under fire. Journal of Southeast University (Natural Science Edition), 35 (sup (I)): 66-68.

[16] EN 1994-1-2 (2005). Eurocode 4 - Design of composite steel and concrete structures - Part 1-2: General rules - Structural fire design. European Committee for Standardization (CEN).

[17] Irfanoglu, A. (2012). Using numerical simulations and engineering reasoning under uncertainty: study of the collapse of WTC-1. Computer-aided Civil and Infrastructure Engineering, 27: 65-76. https://doi.org/10.1111/j.1467-8667.2010.00700.x

[18] McAllister, T.P., Sadek, F., Gross, J.L., Kirkpatrick, S., MacNeill, R., Bocchieri, R.T. (2013). Structural analysis of impact damage to world trade center buildings 1, 2, and 7. Fire Technology, 49: 615-642. https://doi.org/10.1007/s10694-012-0286-5

[19] LSTC (2016). LS-DYNA 971 user's manual, volume I to II (version R9.0.1). Livermore Software Technology Corporation (LSTC), Livermore.

[20] Lu, W., Mäkeläinen, P., Outinen, J., Ma, Z. (2012). Investigation of behavior of cold-formed steel sheeting systems in fire using finite element modelling. Proceedings of the $21^{\text {th }}$ International Specialty Conference on Cold-Formed Steel Structures, St. Louis, Missouri, U.S.A., October 24-25, 2012.

[21] Ali, F., O'Connor, D. (2001). Structural performance of rotationally restrained steel columns in fire. Fire Safety Journal, 36: 679-691. https://doi.org/10.1016/s0379-7112(01)00017-0

[22] Yun, X., Gardner, L. (2017). Stress-strain curves for hot-rolled steels. Journal of Constructional Steel Research, 133: 36-46.

https://doi.org/10.1016/j.jcsr.2017.01.024 
Zhongcheng Ma, Jarmo Havula

Sheet Metal Center, School of Technology

Häme University of Applied Sciences

Visakaarre 9, 13100 Hämeenlinna

Finland

zhongcheng.ma@hamk.fi, jarmo.havula@hamk.fi

Markku Heinisuo

Tampere University of Technology

Department of Civil Engineering

P.O.Box 600, FI-33101 Tampere

Finland

markku.heinisuo@tut.fi 